\title{
One Neglected Yawning Function like Slow Wave Sleep: The Hypothetic Neurovascular Regulation from Mouth to Eye Driven by Expiration
}

\author{
Zi-Jian Cai \\ CaiFortune Consulting, Suzhou, China \\ Email:hrsh8@126.com
}

How to cite this paper: Cai, Z.-J. (2018) One Neglected Yawning Function like Slow Wave Sleep: The Hypothetic Neurovascular Regulation from Mouth to Eye Driven by Expiration. Open Access Library Journal, 5: e4649.

https://doi.org/10.4236/oalib.1104649

Received: May 8, 2018

Accepted: June 3, 2018

Published: June 6, 2018

Copyright (๑) 2018 by author and Open Access Library Inc.

This work is licensed under the Creative Commons Attribution International License (CC BY 4.0).

http://creativecommons.org/licenses/by/4.0/

\begin{abstract}
In this article, it is considered that the mechanism of yawning function is correlative to sleep. It was revealed from the electrophysiological studies that the slow wave sleep (SWS) was characterized as decrease in excitation from inspiratory motoneurons more than from expiration, manifesting the expiratory activity dominating in SWS. To analogize yawning to SWS, herein it is only considered the expiration during yawning, pressing the sensory posterior palate and maxillary sinuses with air flow, so that yawns similarly regulate the vascular circulations from mouth to eye as SWS, as evidenced by the closure of eyelid in sleep and the association of ophthalmic diseases with obstructive sleep apnea. Besides, it is pointed out that the yawning expiration of high muscular tone elicits the muscular constriction at the back of neck, potentiating the expiratory press in mouth stronger than that of SWS. Accordingly, it is hypothesized that the yawning resembles the SWS to play the neurovascular regulation in head driven by expiration. It is speculated that the initiative mouth opening in yawns may have functions other than that considered here. It is expected that this new and neglected function of yawning with expiratory neurovascular regulation in head may add more to understand the complex functions of yawns.
\end{abstract}

\section{Subject Areas}

Neuroscience, Psychiatry \& Psychology, Neurology

\section{Keywords}

Yawn, Slow Wave Sleep, Expiration, Obstructive Sleep Apnea, Neurovascular Regulation of Head, Eyelid 


\section{Introduction}

It is common knowledge that yawning is the correlative behavior of sleep, while frequently occurring before and after sleep with lower levels of alertness, Whereas, the functions of yawns have still been the unsolved enigmas to the scientists [1]. In this paper, it is considered that the mysterious yawning function is in relevance to the functions of slow wave sleep (SWS), which is the period of sleep occurring on the early stage of sleep producing slow waves with a range of frequency from $0.5 \mathrm{~Hz}$ to $2 \mathrm{~Hz}$ and peak-to-peak amplitude greater than $75 \mu \mathrm{V}$. It is attempted to hypothesize an intuitive physiological mechanism underlying the shared function of yawns and SWS.

\section{The Various Postulated Functions of Yawns}

Scientists have postulated various functions for yawns up to now, mainly as the followings:

1) For several centuries, the scientists have thought that yawns might remove "bad air" from the lungs and increase oxygen circulation in the brain, known as the respiratory and circulatory hypotheses [1]. However, some experiments did not support this function of yawns, because the gas mixtures with high levels of $\mathrm{CO}_{2}$ or physical exercise did not produce yawns more frequently [1] [2], while the exercise sufficient to double breathing rate had no effect on yawns [1] [2].

2) It has been suggested yawning more compatible with sleepiness hypothesis rather than arousal hypothesis [1] because yawns occurred most frequently before and after sleep with lower levels of alertness [1] whereas did not produce an EEG arousal [1] [3] [4]. In this regard, it is reasonable to consider the function of yawning as relevant to the induction of sleep or even the function of sleep at early stage.

3) Recently, Gallup and his colleagues have hypothesized the function of yawns from its underlying physiological mechanism as brain cooling thermoregulation [5] [6], presumably via the facial paranasal sinuses [7]. Because brain cooling thermoregulation can only be accomplished via neurovascular regulation of head, it is enlightened from this hypothesis and related experiments that the neurovascular regulation of head should be the underlying physiological mechanism related to the function of yawning, while brain cooling thermoregulation may be one manifestation of the neurovascular regulation of head.

4) There is another hypothesis on yawning function nowadays. Thompson suggested that, because yawns often occurred under stress or tiredness, the yawning function might be linked to the decrease of cortisol level [8]. Besides, recently it was as well demonstrated in primates that yawning played function against anxiety [9]. However, this hypothesis neglects the mechanism of neurovascular regulation, which can certainly accomplish the yawning function against stress, tiredness or anxiety, while the decrease of cortisol level may be the oversimplified one of the related consequences of yawns against stress/tiredness.

5) Besides the physiological functions of yawns, it has also been hypothesized 
the social/communicative functions of yawns [1]. Although the human yawns occur more frequently in the relative absence of social stimulation, the yawns in the other species such as wolves are more frequent in the association with social stimulation [10].

In Table 1, it listed the updated hypothesized yawning functions and the related physiological mechanisms. From these various postulated yawning functions and the related supporting experiments, it can restrict the yawning functions to a narrower range. From (2) in this section, it restricts the yawning function as relevant to the induction of sleep or even the function of sleep at early stage. From (3) in this section, it restricts the yawning function to the neurovascular regulation of head, which can also account for the yawning functions as release of stress or tiredness in (4) in this section. The social/communicative yawning functions in (5) in this section are irrelevant to human yawns and beyond the physiological mechanisms considered in this paper.

In brief, it can be integratively concluded in this section that the yawning function is related to the neurovascular regulation in head relevant to sleep.

\section{The Similar Function of SWS against Stress and Depression}

As mentioned above, the yawning function is relevant to the induction of sleep or even the function of sleep at early stage. There are many functions of sleep, and of SWS at the early stage of sleep. Similar to the yawning function on the release of stress/tiredness, there has really been proposed a SWS function against stress and depression [11] [12] [13] [14], based on that the depressive patients manifested the symptoms of anxiety, tiredness, insomnia and so on [15] [16].

The role of SWS against depression and stress was postulated by the author Cai together with memory processing [11] [12] [13], and by Kupfer and Reynolds together with aging and dementia [14]. Despite the difference in theoretical account, clinical observations and behavioral experiments supporting the role of SWS in emotional regulation have accumulated for a long time in many aspects, as summarized in the followings: shorter duration of SWS has been

Table 1. Summary of the updated yawning functions/physiologies.

\begin{tabular}{lll}
\hline \multicolumn{2}{c}{ Hypothesis } & \multicolumn{1}{c}{ Physiology } \\
\hline (1) $\begin{array}{l}\text { Respiratory/circulatory } \\
\text { hypotheses [1] }\end{array}$ & $\begin{array}{l}\text { Not favored because high } \mathrm{CO}_{2} \text { or physical exercise did not } \\
\text { produce more yawns [1] [2]. }\end{array}$ \\
(2) Sleepiness hypothesis [1] & $\begin{array}{l}\text { Yawns often occur around sleep without producing EEG } \\
\text { arousal [1] [3] [4]. }\end{array}$ \\
(3) $\begin{array}{l}\text { Brain cooling } \\
\text { thermoregulation [5] [6] }\end{array}$ & $\begin{array}{l}\text { Brain cooling via paranasal sinuses [7] can implicate that } \\
\text { yawns regulate the neurovascular balance in head. }\end{array}$ \\
(4) Decrease of cortisol level [8] & $\begin{array}{l}\text { This may be the oversimplified one of the related } \\
\text { consequences of yawns against stress/tiredness. }\end{array}$ \\
(5) $\begin{array}{l}\text { Social/communicative } \\
\text { functions [1] }\end{array}$ & Irrelevant to human yawns.
\end{tabular}


reported to be frequently associated with depression for decades of years up to now [17] [18] [19], while sleep deprivation frequently results in negative mood disturbances characterized as depression, anxiety, frustration, tension and so on in healthy adults [20], and selective deprivation of stage 4 SWS in humans was reported to produce a depressive or hypochondriacal state [21]. In contrast, it has been successfully adopted for decades of years to help ameliorate depression by increasing the duration of SWS in early sleep with phase advance of sleep [22] [23]. In consistency, the high delta sleep ratio might help prevent the early recurrence of unipolar affective disorder [24]. Besides, hippocampal lesion but not neocortical lesion caused impairment of SWS [25], while the neuronal activity in SWS increased in hippocampus but not in neocortex [26] [27] [28]. In all, it is evident that SWS plays a role in limbic and emotional regulation, especially against depression and stress.

With regard to the concurrent memory processing in SWS, it has been shown that the SWS might help retention of declarative memory in humans [29] [30], while impair memory in emotional learning tasks in animals [31] [32]. At the cellular level, it was shown that SWS favored long-term depression (LTD) [33] [34] but not long-term potentiation (LTP) [35] [36].

The underlying LTD in SWS may partly account for how the SWS adjusts the emotional balance against depression and stress. However, it is not sufficient to manifest the peripheral physiological changes brought about by SWS. Because the neurovascular regulation in head is relevant to yawning function as mentioned above, it is definitely necessary to additionally consider how the SWS regulates the neurovascular system in head.

\section{The Parallel Expiratory Driving Neurovascular Regulation in Head during Yawning and SWS}

Yawning consists of an involuntary sequence of mouth opening, deep inspiration, brief apnea, and slow expiration [1] [37], driven by the movements of mouth and respiration. Increases in heart rate, lung volume, and eye muscle tension have been reported during or immediately following yawning [37].

SWS manifests decrease in blood pressure [38] and complex regulation of heart rate [39]. In electrophysiology, it has been demonstrated that the sleep-wake state can modulate the inspiratory motoneurons of respiration, while the tonic expiratory units are largely unaffected by the sleep-wake state [40]. Besides, it has also been demonstrated that the obstructive sleep apnea is closely related to expiratory breath [41] [42]. Both of these observations demonstrate that the expiratory activity dominates in SWS.

The air flow in SWS can certainly press against the sensory posterior palate and maxillary sinuses, which can in turn elicit neurovascular regulation in head. It has been reported that the palate may cause snoring and obstructive sleep apnea [43], while the maxillary expansion can treat the obstructive sleep apnea [44], demonstrating the presence of pressure from the expiratory air flow in SWS onto the posterior palate and maxillary sinuses. 
To analogize the yawns to SWS, their common expiratory activity would certainly be accounted into consideration. In both yawns and SWS, the expiration drives the air flow to press against the sensory posterior palate and maxillary sinuses, which would in further elicit neurovascular regulation in head. In contrast to the domination of expiratory activity in SWS, the yawning expiration is slow and seems less dominant than its inspiration with mouth opening. This needs explanation. It is necessary to point out that in yawns the expiration of high muscular tone can elicit the muscular constriction at the back of neck and potentiate the pressing of air against the sensory posterior palate and maxillary sinuses, which is stronger than that of SWS.

Besides the expiration of high muscular tone, the yawns are initiated saliently with mouth opening and inspiration [1] [37]. Obviously, mouth opening directly presses the blood in the head, but different from SWS without mouth opening so big. Because of its difference from SWS, it is not considered the mouth opening in this paper, which can be further investigated elsewhere in future.

\section{The Parallel Neurovascular Regulation in Head up to Eye during Yawning and SWS}

The similarity of yawns and SWS in neurovascular regulation of head should be inspected not only in their sensation via expiratory pressing against the sensory posterior palate and maxillary sinuses, but also in their consequence of neurovascular regulation in head.

In SWS, the above stated expiratory pressing of air against the sensory posterior palate and maxillary sinuses can be relayed up to the vascular circulation in eyes. For evidence, on the one hand, it is common knowledge that the sleep need close the eyelids. It has been demonstrated that the closure or tiredness of eyelids manifest the extent of drowsiness and sleepiness [45] [46]. On the other hand, the expiration in SWS can really regulate the vascular circulation in eyes. It has been demonstrated that many vascular diseases of eyes are associated with the obstructive sleep apnea, such as the glaucoma, retinal vein occlusion, nonarteritic anterior ischemic optic neuropathy, central serous chorioretinopathy, floppy eyelid syndrome and so on [47] [48]. In the obstructive sleep apnea, the inspiration can still affect the eye in the same way as in normal subjects, while the expiration is affected somewhat on pressing the posterior palate and maxillary sinuses because of the physical obstacle.

In yawns, the neurovascular regulation in head can also reach up to eye, as evidenced by the collection of tears from yawns [49] [50]. The tears in yawns may be produced by either mouth opening or expiration. However, because crying can produce many tears mainly by expiration, it is reasonable to deduce that the expiration in yawns would similarly contribute to the generation of yawning tears, demonstrating the expiratory driving neurovascular regulation in yawns can also affect up to eye as in SWS.

In all, the parallel neurovascular regulation in head from the expiratory pressure onto the sensory posterior palate and maxillary sinuses by both the yawns 
and SWS can be relayed up to affect the vascular circulation in eyes.

\section{Discussions}

Yawning is the behavior closely correlated to sleep. Thus, it is reasonable to consider the yawning function together with that of SWS.

There have been postulated various functions of yawns, such as the clearance of "bad air" from lungs [1] [2], the sleepiness hypothesis [1] [3] [4], the brain cooling thermoregulation [5] [6], the release of stress [8] or anxiety [9], the social/communicative yawning functions [1], and so on. Collectively, it can be summarized from these updated studies of yawning functions that the yawning function is related to the neurovascular regulation in head during drowsiness around sleep.

Closely related to such yawning function, the function of SWS on neurovascular regulation in head need be considered. The electrophysiological observations have demonstrated that the expiratory activity dominates in SWS [40]. The expiratory air flow in SWS can press against the sensory posterior palate and maxillary sinuses, and elicit the neurovascular regulation in head, as having been demonstrated that the palate may cause snoring and obstructive sleep apnea [43], while the maxillary expansion may treat the obstructive sleep apnea [44]. Besides, such expiratory neurovascular regulation in head in SWS can further be relayed up to eye, as evidenced by that many vascular diseases of eyes are associated with the obstructive sleep apnea [47] [48], in which the inspiration can still affect the eye similarly as in normal subjects while the expiration is affected somewhat from pressing the posterior palate and maxillary sinuses due to the physical obstacle.

Because of the correlative nature of yawns to sleep, it is only considered the yawning expiration in this article. In yawns, the neurovascular regulation in head by yawning expiration can also affect up to eye as in SWS, which can be evidenced by the collection of tears from yawns [49] [50] as from crying.

In contrast to the domination of expiratory activity in SWS, the yawning expiration is slow and seems less dominant than the yawning inspiration with mouth opening. This is the reason why the expiratory function of yawns has been neglected somewhat. However, it is necessary to specially point out that in yawns the expiration of high muscular tone can elicit the muscular constriction at the back of neck, which potentiates the expiratory press against the sensory posterior palate and maxillary sinuses, and makes the expiratory press stronger than that of SWS.

The yawns are initiated with mouth opening and inspiration [1] [37]. Mouth opening in yawns is different from SWS without mouth opening so big. Because of its difference from SWS, it is not considered the yawning mouth opening in this paper. The initiative mouth opening in yawns may have functions other than that of SWS. It is definitely important to further investigate the functions of mouth opening in yawns in future.

In contrast to the difference in the functions of mouth opening in yawns to 
SWS, the expiratory driving function of yawns is perspective in its intimate analogy to the physiology and function of SWS in both regulating the neurovascular balance in head and the wake-sleep status in eye, so that not only manifesting the physiological mechanism to accomplish the shared expiratory driving function of yawns and SWS, but also enlightening the comprehension of the wake-sleep transition. Obviously, it is important to further promote the investigation of this subject in future.

It is certainly necessary to call for more research on the various functions of yawns. The yawning behavior is closely correlated to sleep, which can not only accomplish a portion of sleep functions, but also provide some useful clues to understanding the complex mechanisms of sleep functions.

\section{Conclusions}

In this article, due to the correlative nature of yawning behavior to sleep, it is considered the mechanism of yawning function in parallel to that of SWS. From reviewing the various updated yawning functions, it is summarized that the yawning function is related to the neurovascular regulation in head during drowsiness around sleep.

It is demonstrated that the expiratory activity dominates in SWS because the SWS has been reported as decrease in excitation from inspiratory motoneurons more than from expiration. The expiratory neurovascular regulation in SWS via pressing the sensory posterior palate and maxillary sinuses in head with air flow can further be relayed up to eye, as evidenced by many vascular diseases of eyes in association with the obstructive sleep apnea.

To analogize the yawning function to that of SWS, in this article it is only considered the yawning expiration, which presses the sensory posterior palate and maxillary sinuses with air flow, so that similarly regulates the vascular circulations from mouth to eye as SWS. The expiration of high muscular tone in yawns can elicit the muscular constriction at the back of neck, and potentiate the pressing of air against the sensory posterior palate and maxillary sinuses stronger than that of SWS. Via this mechanism of potentiated expiratory air pressure, the neglected yawning expiration resembles the SWS to regulate the neurovascular system in head. Whereas, the mouth opening in yawns may have functions other than that considered here.

\section{Acknowledgements}

It is herein acknowledged that MingXun Cai pays the Open Access publication fee of this paper.

\section{Funding}

The author declares no financial support for this work.

\section{Conflict of Interest Statement}

The author declares no conflict of interest for this work. 


\section{References}

[1] Guggisberg, A.G., Mathis, J., Schnider, A. and Hess, C.W. (2010) Why Do We Yawn? Neuroscience \& Biobehavioral Reviews, 34, 1267-1276. https://doi.org/10.1016/j.neubiorev.2010.03.008

[2] Provine, R.R., Tate, B.C. and Geldmacher, L.L. (1987) Yawning: No Effect of 3-5\% $\mathrm{CO}_{2}, 100 \% \mathrm{O}_{2}$, and Exercise. Behavioral and Neural Biology, 48, 382-393. https://doi.org/10.1016/S0163-1047(87)90944-7

[3] Guggisberg, A.G., Mathis, J. and Hess, C.W. (2010) Interplay between Yawning and Vigilance: A Review of the Experimental Evidence. Frontiers of Neurology and Neuroscience, 28, 47-54. https://doi.org/10.1159/000307079

[4] Guggisberg, A.G., Mathis, J., Herrmann, U.S. and Hess, C.W. (2007) The Functional Relationship between Yawning and Vigilance. Behavioural Brain Research, 179, 159-166. https://doi.org/10.1016/j.bbr.2007.01.027

[5] Gallup, A.C. (2010) A Thermoregulatory Behavior. Frontiers of Neurology and Neuroscience, 28, 84-89. https://doi.org/10.1159/000307084

[6] Massen, J.J., Dusch, K., Eldakar, O.T. and Gallup, A.C. (2014) A Thermal Window for Yawning in Humans: Yawning as a Brain Cooling Mechanism. Physiology \& Behavior, 130, 145-148. https://doi.org/10.1016/j.physbeh.2014.03.032

[7] Gallup, A.C. and Hack, G.D. (2011) Human Paranasal Sinuses and Selective Brain Cooling: A Ventilation System Activated by Yawning? Medical Hypotheses, 77, 970-973. https://doi.org/10.1016/j.mehy.2011.08.022

[8] Thompson, S.B. (2011) Born to Yawn? Cortisol Linked to Yawning: A New Hypothesis. Medical Hypotheses, 77, 861-862.

https://doi.org/10.1016/j.mehy.2011.07.056

[9] Zannella, A., Norscia, I., Stanyon, R. and Palagi, E. (2015) Testing Yawning Hypotheses in Wild Populations of Two Strepsirrhine Species: Propithecus verreauxi and Lemur catta. American Journal of Primatology, 77, 1207-1215. https://doi.org/10.1002/ajp.22459

[10] Romero, T., Ito, M., Saito, A. and Hasegawa, T. (2014) Social Modulation of Contagious Yawning in Wolves. PLOS ONE, 9, e105963. https://doi.org/10.1371/journal.pone.0105963

[11] Cai, Z.J. (1991) The Functions of Sleep: Further Analysis. Physiology \& Behavior, 50, 53-60. https://doi.org/10.1016/0031-9384(91)90497-C

[12] Cai, Z.J. (1995) An Integrative Analysis to Sleep Functions. Behavioural Brain Research, 69, 187-194. https://doi.org/10.1016/0166-4328(95)00005-E

[13] Cai, Z.J. (2016) Progressions of Sleep, Memory and Depression Applicable to Psychoanalysis: A Review. Current Psychiatry Reviews, 12, 240-245. https://doi.org/10.2174/1573400512666160610083505

[14] Kupfer, D.J. and Reynolds, C.F. (1989) Slow-Wave Sleep as a "Protective" Factor. In: Stunkard, A.J. and Baum, A., Eds., Perspectives in Behavioral Medicine: Eating, Sleeping, and Sex, Lawrence Erlbaum Associates Inc., New Jersey, 131-145.

[15] Baldwin, D.S. and Papakostas, G.I. (2006) Symptoms of Fatigue and Sleepiness in Major Depressive Disorder. The Journal of Clinical Psychiatry, 67, 9-15.

[16] Fava, M., Ball, S., Nelson, J.C., Sparks, J., Konechnik, T., Classi, P., Dube, S. and Thase, M.E. (2014) Clinical Relevance of Fatigue as a Residual Symptom in Major Depressive Disorder. Depression and Anxiety, 31, 250-257. https://doi.org/10.1002/da.22199

[17] Baglioni, C., Spiegelhalder, K., Feige, B., Nissen, C., Berger, M. and Riemann, D. 
(2014) Sleep, Depression and Insomnia-A Vicious Circle? Current Psychiatry Reviews, 10, 202-213. https://doi.org/10.2174/1573400510666140620001507

[18] Medina, A.B., Lechuga, D.A., Escandón, O.S. and Moctezuma, J.V. (2014) Update of Sleep Alterations in Depression. Sleep Science, 7, 165-169. https://doi.org/10.1016/j.slsci.2014.09.015

[19] Mendlewicz, J. and Kerkhofs, M. (1991) Sleep Electroencephalography in Depressive Illness. A Collaborative Study by the World Health Organization. The British Journal of Psychiatry, 159, 505-509. https://doi.org/10.1192/bjp.159.4.505

[20] Kahn-Greene, E.T., Killgore, D.B., Kamimori, G.H., Balkin, T.J. and Killgore, W.D. (2007) The Effects of Sleep Deprivation on Symptoms of Psychopathology in Healthy Adults. Sleep Medicine, 8, 215-221. https://doi.org/10.1016/j.sleep.2006.08.007

[21] Agnew Jr., H.W., Webb, W.B. and Williams, R.L. (1967) Comparison of Stage Four and 1-REM Sleep Deprivation. Perceptual \& Motor Skills, 24, 851-858. https://doi.org/10.2466/pms.1967.24.3.851

[22] Wehr, T.A., Wirz-Justice, A., Goodwin, F.K., Duncan, W. and Gillin, J.C. (1979) Phase Advance of the Circadian Sleep-Wake Cycle as an Antidepressant. Science, 206, 710-713. https://doi.org/10.1126/science.227056

[23] Bunney, B.G. and Bunney, W.E. (2012) Rapid-Acting Antidepressant Strategies: Mechanisms of Action. International Journal of Neuropsychopharmacology, 15, 695-713. https://doi.org/10.1017/S1461145711000927

[24] Kupfer, D.J., Frank, E., McEachran, A.B. and Grochocinski, V.J. (1990) Delta Sleep Ratio. A Biological Correlate of Early Recurrence in Unipolar Affective Disorder. Archives of General Psychiatry, 47, 1100-1105. https://doi.org/10.1001/archpsyc.1990.01810240020004

[25] Kim, C., Choi, H., Kim, J.K., Kim, M.S., Huh, M.K. and Moon, Y.B. (1971) Sleep Pattern of Hippocampectomized Cat. Brain Research, 29, 223-236. https://doi.org/10.1016/0006-8993(71)90030-8

[26] McGinty, D. and Szymusiak, R. (1988) Neuronal Unit Activity Patterns in Behaving Animals: Brainstem and Limbic System. Annual Review of Psychology, 39, 135-168. https://doi.org/10.1146/annurev.ps.39.020188.001031

[27] Winson, J. and Abzug, C. (1977) Gating of Neuronal Transmission in the Hippocampus: Efficacy of Transmission Varies with Behavioral State. Science, 196, 1223-1225. https://doi.org/10.1126/science.193192

[28] Steriade, M. and Hobson, J. (1976) Neuronal Activity during the Sleep-Waking Cycle. Progress in Neurobiology, 6, 157-376. https://doi.org/10.1016/0301-0082(76)90013-7

[29] Rasch, B. and Born, J. (2013) About Sleep's Role in Memory. Physiological Reviews, 93, 681-766. https://doi.org/10.1152/physrev.00032.2012

[30] Inostroza, M. and Born, J. (2013) Sleep for Preserving and Transforming Episodic Memory. Annual Review of Neuroscience, 36, 79-102. https://doi.org/10.1146/annurev-neuro-062012-170429

[31] Hars, B. and Hennevin, E. (1987) Impairment of Learning by Cueing during Postlearning Slow-Wave Sleep in Rats. Neuroscience Letters, 79, 290-294. https://doi.org/10.1016/0304-3940(87)90446-0

[32] Rideout, B.E. (1979) Non-REM Sleep as a Source of Learning Deficits Induced by REM Sleep Deprivation. Physiology \& Behavior, 22, 1043-1047.

https://doi.org/10.1016/0031-9384(79)90254-3 
[33] Yang, Z., Zhang, W., Wang, M., Ruan, D. and Chen, J. (2012) Effects of Daytime, Night and Sleep Pressure on Long-Term Depression in the Hippocampus in Vivo. Neuroscience Letters, 511, 106-109. https://doi.org/10.1016/j.neulet.2012.01.050

[34] Yang, Z., Zhang, W., Wang, M., Ruan, D. and Chen, J. (2012) Effect of Low Intensity Low-Frequency Stimuli on Long-Term Depression in the Rat Hippocampus Area CA1 in Vivo. Neuroscience Letters, 523, 24-29. https://doi.org/10.1016/j.neulet.2012.06.034

[35] Leonard, B.J., McNaughton, B.L. and Barnes, C.A. (1987) Suppression of Hippocampal Synaptic Plasticity during Slow-Wave Sleep. Brain Research, 425, 174-177. https://doi.org/10.1016/0006-8993(87)90496-3

[36] Bramham, C.R. and Srebro, B. (1989) Synaptic Plasticity in the Hippocampus Is Modulated by Behavioral State. Brain Research, 493, 74-86.

https://doi.org/10.1016/0006-8993(89)91001-9

[37] Corey, T.P., Shoup-Knox, M.L., Gordis, E.B. and Gallup Jr., G.G. (2012) Changes in Physiology before, during, and after Yawning. Frontiers in Evolutionary Neuroscience, 3, 7. https://doi.org/10.3389/fnevo.2011.00007

[38] Silvani, A. and Dampney, R.A. (2013) Central Control of Cardiovascular Function during Sleep. American Journal of Physiology-Heart and Circulatory Physiology, 305, H1683-H1692. https://doi.org/10.1152/ajpheart.00554.2013

[39] Burgess, H.J., Holmes, A.L. and Dawson, D. (2001) The Relationship between Slow-Wave Activity, Body Temperature, and Cardiac Activity during Nighttime Sleep. Sleep, 24, 343-349. https://doi.org/10.1093/sleep/24.3.343

[40] Trinder, J., Jordan, A.S. and Nicholas, C.L. (2014) Discharge Properties of Upper Airway Motor Units during Wakefulness and Sleep. Progress in Brain Research, 212, 59-75. https://doi.org/10.1016/B978-0-444-63488-7.00004-5

[41] Oliveira, L.V., Romano, S., Hirata, R.P., Faria Júnior, N.S., Giannasi, L.C., Nacif, S.R., Leitão Filho, F.S. and Insalaco, G. (2011) Negative Expiratory Pressure Test: A New, Simple Method to Identify Patients at Risk for Obstructive Sleep Apnea. Jornal Brasileiro de Pneumologia, 37, 659-663. https://doi.org/10.1590/S1806-37132011000500014

[42] Bikov, A., Hull, J.H. and Kunos, L. (2016) Exhaled Breath Analysis, a Simple Tool to Study the Pathophysiology of Obstructive Sleep Apnoea. Sleep Medicine Reviews, 27, 1-8. https://doi.org/10.1016/j.smrv.2015.07.005

[43] MacLean, J.E., Fitzsimons, D., Fitzgerald, D. and Mbbs, K.W. (2017) Comparison of Clinical Symptoms and Severity of Sleep Disordered Breathing in Children with and without Cleft Lip and/or Palate. The Cleft Palate-Craniofacial Journal, 54, 523-529. https://doi.org/10.1597/15-309

[44] Vale, F., Albergaria, M., Carrilho, E., Francisco, I., Guimarães, A., Caramelo, F. and Maló, L. (2017) Efficacy of Rapid Maxillary Expansion in the Treatment of Obstructive Sleep Apnea Syndrome: A Systematic Review with Meta-Analysis. Journal of Evidence-Based Dental Practice, 17, 159-168. https://doi.org/10.1016/j.jebdp.2017.02.001

[45] Filtness, A.J., Anund, A., Fors, C., Ahlström, C., Akerstedt, T. and Kecklund, G. (2014) Sleep-Related Eye Symptoms and Their Potential for Identifying Driver Sleepiness. Journal of Sleep Research, 23, 568-575. https://doi.org/10.1111/jsr.12163

[46] Alvaro, P.K., Jackson, M.L., Berlowitz, D.J., Swann, P. and Howard, M.E. (2016) Prolonged Eyelid Closure Episodes during Sleep Deprivation in Professional Drivers. Journal of Clinical Sleep Medicine, 12, 1099-1103. 
https://doi.org/10.5664/jcsm.6044

[47] Huon, L.K., Liu, S.Y., Camacho, M. and Guilleminault, C. (2016) The Association Between Ophthalmologic Diseases and Obstructive Sleep Apnea: A Systematic Review and Meta-Analysis. Sleep and Breathing, 20, 1145-1154.

https://doi.org/10.1007/s11325-016-1358-4

[48] Skorin Jr., L. and Knutson, R. (2016) Ophthalmic Diseases in Patients with Obstructive Sleep Apnea. The Journal of the American Osteopathic Association, 116, 522-529. https://doi.org/10.7556/jaoa.2016.105

[49] Choy, C.K., Cho, P., Chung, W.Y. and Benzie, I.F. (2001) Water-Soluble Antioxidants in Human Tears: Effect of the Collection Method. Investigative Ophthalmology \& Visual Science, 42, 3130-3134.

[50] Choy, C.K., Benzie, I.F. and Cho, P. (2004) Is Ascorbate in Human Tears from Corneal Leakage or from Lacrimal Secretion? Clinical and Experimental Optometry, 87, 24-27. https://doi.org/10.1111/j.1444-0938.2004.tb03142.x 